Original Article

\title{
SUSTAINED RELEASE MUCOADHESIVE MICROCAPSULES OF RAMIPRIL BY IONIC GELATION TECHNIQUE: FORMULATION DESIGN, OPTIMIZATION AND CHARACTERIZATION
}

\author{
KORLAPATI VENKATESWARA RAO*, V. V. VENKATCHALAM \\ Department of Pharmacy, Annamalai University, Annamalainagar 608002, Tamilanadu, India \\ Email: kvraophdscholar@gmail.com
}

Received: 07 May 2016 Revised and Accepted: 21 Dec 2016

\section{ABSTRACT}

Objective: The major objective of the research work was to design, optimise and characterise sodium alginate based sustained release mucoadhesive microcapsules of ramipril by ionic gelation method.

Methods: An experimental set-up was designed to investigate the optimal combination of mucoadhesive polymers such as carbopol 974P, HPMC (K4M and K100M), Na CMC and chitosan and their drug compatibility with respect to reliabilities. Preliminary screening of the formulation variables was accomplished by Taguchi design followed by Box-Behnken design for systematic optimisation. The suitable mathematical model was selected, response surface analysis was performed and optimised formulation was chosen by numerical optimization and desirability function method. Characterization of the prepared microcapsules for several inherent properties like particle size, drug content, sphericity, entrapment efficiency, loose surface crystal study, swelling index, micromeritic properties, moisture content, in vitro drug release, mucoadhesive strength and in vivo antihypertensive activity was performed.

Results: Differential Scanning Calorimetry (DSC) thermograms and Fourier Transform Infra-Red (FT-IR) spectral studies revealed no incompatibility between the pure drug and selected polymers. The spherical nature of the prepared microcapsules was established by surface morphology studies.

Conclusion: The resultant sustained release mucoadhesive microcapsules of ramipril remained stable when subjected to stress conditions unveiling it as a better alternative delivery system with superior therapeutic efficacy.

Keywords: Taguchi design, Box-Behnken design, Antihypertensive activity, Percentage bioadhesion, Sustained release

(C) 2017 The Authors. Published by Innovare Academic Sciences Pvt Ltd. This is an open access article under the CC BY license (http://creativecommons.org/licenses/by/4. 0/) DOI: http://dx.doi.org/10.22159/ijpps.2017v9i2.12660

\section{INTRODUCTION}

The oral route is most sought-after for the administration of drug molecules to the systemic circulation due to ease of administration, better treatment and (or) patient compliance and costeffective [1]. Despite the tremendous strides in oral drug delivery systems, the success of conventional dosage forms is limited and often uttered by inadequate drug residence time in the stomach and small intestine [2]. On the contrary, the oral sustained release dosage forms have merits of reduced dosing frequency, enhanced gastric residence time, and provide desired therapeutic clinical benefits [3] Mucoadhesive microcapsules are the multiple unit particulate systems contain mucoadhesive polymers, which provide sustained release action upon intimate contact with the epithelial mucous membrane lining $[4,5]$. Also, such formulation protects the drug from the gastric acidic environment, increases the oral bioavailability of drugs and reduces the variability. Ramipril, an orally long active angiotensinconverting-enzyme (ACE) inhibitor is a drug of choice for the treatment of mild to severe hypertension and congestive heart failure. However, due to the poor aqueous solubility and high first pass metabolism it often suffers from low bioavailability and poor treatment. Being a highly lipophilic drug, ramipril exhibits variable oral absorption and increasing the aqueous solubility, and dissolution is of greater therapeutic importance [6-10]. The conventional dosage forms available in the market fail to satiate the needs of enhancing the oral bioavailability and to improve the patient compliance. This calls for the development of ramipril loaded novel mucoadhesive multiparticulate drug delivery systems to enhance its oral bioavailability with improved pharmacodynamic potential $[11,12]$. Optimisation of pharmaceutical experiments involving both product and process are being practiced widely for the systematic development of dosage forms. The design of Experiment (DoE) methodology, in this regard, helps in designing the experiments by a complete understanding of the product and process variables and optimisation of them with the help appropriate experimental design [13, 14]. Examples of various experimental designs used for screening and optimisation of novel drug delivery systems include factorial design, Placket-Burman design, Taguchi design, Central-Composite design, Box-Behnken design (BBD) and mixture design, etc. [15]. As discussed, the mucoadhesive drug delivery systems contain polymers of diverse chemical nature, thus requires optimization of them to obtain the robust formulations with desired therapeutic performance [16].

The present studies, therefore, aims to prepare the mucoadhesive microcapsules of ramipril by ionic gelation technique employing various polymer viz. sodium alginate, carbopol 974P, HPMC K4M, HPMC K100M, Na CMC and chitosan. Initially, different batches of microcapsules were prepared by ionic gelation technique to evaluate the suitability of a particular mucoadhesive polymer. Further, the preliminary prototype formulations were prepared as per suitable screening design, i.e., Taguchi design and evaluated for selecting the influential variables. Further, the mucoadhesive microcapsules were optimised using the Box-Behnken design for influential factors to obtain the robust formulations. The optimised microcapsules were evaluated for physiochemical characterizations, in vitro and drug release. Also, the microcapsules were screened by FT-IR, DSC and SEM for the distribution of drug in solid state characterization and to investigate the morphological shape of the optimized formulation.

\section{MATERIALS AND METHODS}

Ramipril was generously gifted by M/s Ranbaxy Labs Ltd., Gurgaon, India. Various polymers like sodium alginate, HPMC (K4M and K100M) were provided by Colorcon, Goa, India; while Himedia, Mumbai, India, provided $\mathrm{CaCl}_{2}$, carbopol $974 \mathrm{P}, \mathrm{Na} \mathrm{CMC}$ and chitosan. All other chemicals and reagents like potassium dihydrogen phosphate and sodium hydroxide used were of analytical reagent (AR) grade. Deionized water (distilled) was used throughout the experimental procedure. 


\section{Preparation of mucoadhesive microcapsules}

A homogeneous solution was prepared by dissolving required quantities of sodium alginate and selected mucoadhesive polymers in sufficient amount of distilled water. The requisite amount of drug was added to the polymer solution and mixed thoroughly with the help of a mechanical stirrer at a speed of $1000 \mathrm{rpm}$ for $1 \mathrm{~h}$ to form a viscous dispersion. Subsequently, the resultant drug-polymer dispersion was slowly added in a dropwise manner into a previously prepared $10 \%$ $\mathrm{w} / \mathrm{v}$ calcium chloride solution manually with the help of syringe through the 18-size needle. The added droplets were retained for $3 \mathrm{~h}$ in contact with calcium chloride solution to allow complete curing of the reaction and production of spherically rigid microcapsules. The collection and processing of the microcapsules were done by decantation followed by washing with distilled water and drying for $12 \mathrm{~h}$ at $45{ }^{\circ} \mathrm{C}$. The composition of preliminary trial batches of mucoadhesive microcapsule formulations of ramipril is shown in table 1.

Table 1: Preliminary formulation design of mucoadhesive microcapsules (drug: sodium alginate: mucoadhesive polymer: 5: 4: 1) by ionic gelation technique

\begin{tabular}{|c|c|c|c|c|c|c|}
\hline \multirow[t]{2}{*}{ Ingredients (mg) } & \multicolumn{6}{|c|}{ Batch code } \\
\hline & B1 & B2 & B3 & B4 & B5 & B6 \\
\hline Ramipril & 500 & 500 & 500 & 500 & 500 & 500 \\
\hline Sodium alginate & 1600 & 1600 & 1600 & 1600 & 1600 & 1600 \\
\hline Carbopol $974 \mathrm{P}$ & - & 400 & - & - & - & - \\
\hline HPMC K4M & - & - & 400 & - & - & - \\
\hline HPMC K 100M & - & - & - & 400 & - & - \\
\hline $\mathrm{Na} \mathrm{CMC}$ & - & - & - & & 400 & - \\
\hline Chitosan & - & - & - & - & - & 400 \\
\hline $\mathrm{CaCl}_{2}(\% \mathrm{w} / \mathrm{v})$ & 10 & 10 & 10 & 10 & 10 & 10 \\
\hline Distilled water & QS & QS & QS & QS & QS & QS \\
\hline
\end{tabular}

QS: Quantity sufficient

\section{Screening and optimisation of formulations by using experimental designs}

In order to optimize the mucoadhesive microcapsule formulations, initially, the most influential factors were screened out by Taguchi design [17]. A total of seven different factors were selected at their respective ranges for microcapsule formulations to evaluate their effect on the chosen responses, as shown in table 2 . From the study, only significant factors were selected and such factors must be more strictly controlled during the execution of the method. The impact of these factors on the performance criteria of the microcapsule formulations with respect to the desirability of responses was examined by a response surface methodology based BBD. The mucoadhesive microcapsules were prepared as per the suggested experimental runs and examined for key response variables [Drug release (\%), in vitro mucoadhesion (\%), drug entrapment $(\%)$ and particle size $(\mu \mathrm{m})]$.

Thirteen formulations of ramipril is loaded mucoadhesive microcapsules were designed by ionic gelation technique [18]. Five coefficients ( $\beta 1$ to $\beta 5$ ) were calculated with $\beta 0$ as the intercept, as described in the general polynomial Equation-1.

$$
Y=\beta_{0}+\beta_{1} X_{1}+\beta_{2} X_{2+} \beta_{3} X_{3}+\beta_{4} X_{4}+\beta_{5} X_{5}
$$

Table 2: Formulation and process variables with their respective high and low level investigated using Taguich design

\begin{tabular}{|c|c|c|c|c|c|c|c|}
\hline Trials & Sodium alginate & HPMC K100M & Cross-linking time & Calcium chloride & Span 80 & Stirring speed & Stirring time \\
\hline 1 & -1 & -1 & 1 & -1 & -1 & 1 & -1 \\
\hline 2 & -1 & 1 & -1 & 1 & 1 & -1 & 1 \\
\hline 3 & -1 & 1 & 1 & -1 & 1 & 1 & 1 \\
\hline 4 & 1 & 1 & 1 & -1 & -1 & -1 & 1 \\
\hline 5 & 1 & -1 & -1 & -1 & 1 & -1 & 1 \\
\hline 6 & 1 & -1 & -1 & -1 & -1 & 1 & -1 \\
\hline 7 & 1 & 1 & 1 & 1 & 1 & 1 & 1 \\
\hline 8 & 1 & -1 & -1 & 1 & 1 & 1 & -1 \\
\hline
\end{tabular}

Low level (-1); High level (+1): Sod. alginate (mg) 400(-1) and $1600(+1)$; HPMC K100M (mg) 100(-1) and 400(+1); Cross linking time (h) $3(-1)$ and $6(+1)$; Calcium chloride $(\% \mathrm{w} / \mathrm{v}) 5(-1)$ and $15(+1)$; Span $80(\% \mathrm{w} / \mathrm{w}) 3(-1)$ and $5(+1)$; Stirring speed (rpm) $1000(-1)$ and $2000(+1)$ and Stirring time (min), $30(-1)$ and $60(+1)$.

\section{Selection of factor levels}

The results obtained from Taguchi design were analysed comprehensively. Amongst the various screened variables, the most influential factors, i.e., the amounts of Na alginate, HPMC K100M, cross-linking time (h) and conc. of $\mathrm{CaCl}_{2}(\% \mathrm{w} / \mathrm{v})$ were finally selected for further formulation optimisation work. Various mucoadhesive microcapsules were prepared by varying the amounts of Na alginate, HPMC K100M, cross-linking time (h) and conc. of $\mathrm{CaCl}_{2}(\% \mathrm{w} / \mathrm{v})$ in accordance to BBD [19].

The four factors with three levels of low (-), nominal (0) and high (+) were studied in the BBD for 13 experimental runs (table 3). All the experiments were performed in triplicate. The formulations were investigated for drug release (\%), in vitro mucoadhesion (\%), drug entrapment $(\%)$ and particle size $(\mu \mathrm{m})[20]$.

\section{Optimisation data analysis}

Optimisation by BBD facilitates the development of polynomial models to assess the statistical significance of the variable influences being studied including the interaction and quadratic terms for all the responses using the following Equation-2.

$Y=\beta_{0}+\beta_{1} X_{1}+\beta_{2} X_{2}+\beta_{3} X_{1} X_{2}+\beta_{4} X_{12}+\beta_{5} X_{22}+\beta_{6} X_{1} X_{22}+\beta_{7} X_{12}$

Where, $\beta 0$ is the intercept representing the quantitative results of al the experimental runs; $\beta 1$ to $\beta 7$ are the regression coefficients figured out from the predicted response values of Y; X1 to X4 are the independent variables selected from Taguchi design.

Design Expert $\AA$ software (Stat-Ease, USA) was employed to fit second-order polynomial equations with auxiliary tools to correlate 
the examined responses with the studied variables. 3D response curves and contour plots were formed to demonstrate the polynomial regression results. A feasibility search using MS-Excel to find the suitable region for further location of optimum formulation was carried out on the basis of trade-off values of response variables for maximum responses criteria of drug release $(10 \mathrm{~h})>75 \%$, in vitro mucoadhesion $(10 \mathrm{~h})>90 \%$, drug entrapment $>45 \%$ and particle size $>1000 \mu \mathrm{m}$. Within the selected feasible regions, an extensive grid search was subsequently performed to further narrow down the region of the optimal formulation. Overlay contour plot and desirability function tools of the Design Expert software were also employed to locate the optimised formulation.

\section{Validation of the optimisation methodology}

Thirteen formulations were designed to validate the methodology for systematic optimisation as shown in table 3 . The mucoadhesive microcapsules were formulated using the composition given by BBD and evaluated for drug release (\%), in vitro mucoadhesion (\%), drug entrapment $(\%)$ and particle size $(\mu \mathrm{m})$. The observed and predicted responses for the formulations were critically correlated, and the percent prediction error was calculated. Linear correlation plots between predicted and observed responses of the checkpoint formulations were constructed, and the residual graphs were plotted.

Table 3: Obtained responses of selected experimental runs as per Box-Behken design

\begin{tabular}{|c|c|c|c|c|c|c|c|c|}
\hline $\begin{array}{l}\text { Formulation } \\
\text { code }\end{array}$ & $\begin{array}{l}\text { Sodium } \\
\text { alginate } \\
(\mathrm{mg})\end{array}$ & $\begin{array}{l}\text { HPMC } \\
\text { K100M } \\
\text { (mg) }\end{array}$ & $\begin{array}{l}\text { Cross } \\
\text { linking } \\
\text { time (h) }\end{array}$ & $\begin{array}{l}\text { Concentration } \\
\text { of } \mathrm{CaCl}_{2} \\
(\% \mathrm{w} / \mathrm{v})\end{array}$ & $\begin{array}{l}\text { Drug } \\
\text { release } \\
(\%)\end{array}$ & $\begin{array}{l}\text { Mucoadhesion } \\
(\%)\end{array}$ & $\begin{array}{l}\text { Drug } \\
\text { entrapment } \\
(\%)\end{array}$ & $\begin{array}{l}\text { Particle } \\
\text { size }(\mu \mathrm{M})\end{array}$ \\
\hline F1 & -1 & -1 & 0 & 0 & 71.35 & 65 & 12.51 & 1005.43 \\
\hline F2 & 1 & 1 & 0 & 1 & 45.56 & 88 & 12.22 & 1014.22 \\
\hline F3 & -1 & 0 & -1 & 0 & 66.54 & 74 & 22.56 & 1099.15 \\
\hline F4 & 1 & -1 & 0 & 1 & 48.43 & 79 & 31.44 & 1173.59 \\
\hline F5 & 0 & 0 & 0 & 1 & 67.31 & 64 & 21.67 & 1059.87 \\
\hline F6 & -1 & 1 & 0 & -1 & 69.34 & 81 & 11.58 & 1012.42 \\
\hline F7 & 0 & 1 & 1 & -1 & 71.05 & 71 & 33.24 & 1022.13 \\
\hline F8 & 1 & 0 & 1 & 0 & 45.26 & 72 & 13.59 & 1067.28 \\
\hline F9 & 1 & 0 & -1 & 1 & 44.61 & 68 & 23.14 & 1176.43 \\
\hline F10 & 0 & -1 & 1 & -1 & 46.11 & 61 & 32.52 & 1189.45 \\
\hline F11 & -1 & 0 & 1 & -1 & 68.23 & 73 & 31.23 & 1162.36 \\
\hline F12 & 0 & 1 & -1 & 0 & 45.84 & 72 & 30.48 & 1054.65 \\
\hline F13 & 0 & -1 & -1 & 0 & 55.88 & 56 & 28.45 & 1028.12 \\
\hline
\end{tabular}

Low level (-1), int. level (0) and high level (+1): Sodium Alginate (mg) 400, 1000 and 1600; HPMC K100M (mg) 100, 250 and 400; Cross linking time (h) 3, 4.5 and 6 and Concentration of $\mathrm{CaCl}_{2}(\% \mathrm{w} / \mathrm{v}) 5,10$ and 15

\section{Characterization}

\section{Production yield and drug content}

All batches of dried mucoadhesive microcapsules as per the study design were accurately weighed to calculate the percent yield. For calculation of the percent drug content in the prepared microcapsules, an amount of microcapsules, equivalent to $25 \mathrm{mg}$ of ramipril was weighed, powdered, suspended in $100 \mathrm{ml}$ of phosphate buffer $\mathrm{pH} 6.8$ and kept a side for $24 \mathrm{~h}$ for complete solubilization. The resultant dispersion was filtered through a Whattman filter paper and spectrophotometrically measured at $\lambda_{\max } \quad 231 \mathrm{~nm}$ (Shimadzu 1800 UV-ENG240V, Japan) [21]. The total drug content was determined by employing absorbance obtained in the linear regression equation $(\mathrm{Y}=0.010 \mathrm{X}-0.011)$ of the calibration curve.

\section{Drug entrapment efficiency}

The efficiency of drug entrapment was determined spectrophotometrically $\left(\lambda_{\max } 231 \mathrm{~nm}\right)$ using the dispersion containing microcapsules equivalent to $25 \mathrm{mg}$ of ramipril in phosphate buffer ( $\mathrm{pH}$ 6.8). The following equation-3 was used to calculate the drug entrapment efficiency [23]

Entrapment efficiency $=\frac{\text { Actual drug content }}{\text { Theoritical drug content }} \times 100---(3)$

\section{Loose surface crystal study}

Loose surface crystal study was performed to calculate the excess amount of drug present on the surface of prepared microcapsules. For this, $100 \mathrm{mg}$ of microcapsules were shaken in $20 \mathrm{ml}$ of phosphate buffer (pH 6.8) for $5 \mathrm{~min}$ and filtered through $0.45 \mu \mathrm{m}$ membrane filter. The filtrate was taken and analysed spectrophotometrically to determine the amount of drug present [23].

\section{In vitro wash off test}

The mucoadhesive property of the prepared microcapsules was evaluated by the in vitro wash-off technique. Freshly excised a piece of goat intestinal mucosa collected from the local slaughter house were cut into appropriate pieces, and the required pieces were mounted on glass slides tied with thread. About 25 microcapsules were spread out on each piece of the tissue specimen and then hung from the arm of the modified tablet disintegration test apparatus. The disintegrating test apparatus was operated in such a way that the mucosa was exposed to the media (both phosphate buffer $\left(\mathrm{pH}\right.$ 6.8) and $0.1 \mathrm{~N} \mathrm{HCl}$ maintained at $37 \pm 0.5{ }^{\circ} \mathrm{C}$ ), with regular $10-12$ dips per minute. The test was performed up to $6 \mathrm{~h}$ and at a regular interval of $1 \mathrm{~h}$, the total number of microcapsules adhered to the intestinal mucosa were counted, and percentage mucoadhesion was calculated [24]

\section{Percent moisture loss}

Percentage moisture loss for the selected microcapsules formulations was evaluated to know their hydrophobicity. Microcapsules were accurately weighed (W1) and kept in a desicator containing calcium chloride at $37^{\circ} \mathrm{C}$ for $24 \mathrm{~h}$. The weight of the sample was checked at regular interval of time until there is no further change in weight and noted as W2. Finally, the percentage moisture content was determined by equation-4 [25].

$$
\text { Percentage moisture loss }=\frac{\mathrm{W} 1-\mathrm{W} 2}{\mathrm{~W} 1} \times 100-------(4)
$$

\section{Micromeritic properties of microcapsules}

The selected microcapsules formulations were evaluated for various micrometric properties like Carr's index, the angle of repose and Hausner's ratio. All the tests were performed as per the procedure is given in USPXXXI. Fixed funnel method was employed to determine the angle of repose (equation-5). For determination of tapped density, microcapsules were tapped using USP tapped density tester (Electrolab, model ETD-1020, Mumbai) for 100 taps and the change in volume was measured [26]. Equation 6 and 7 were used to calculate Carr's index and Hausner's ratio respectively.

$$
\operatorname{Tan} \Theta=\frac{\mathrm{h}}{\mathrm{r}}-------------------(5)
$$


Where, $\theta$ is the angle of repose, $h=$ height and $r=$ radius of the powder pile in $\mathrm{cm}$.

$$
\begin{aligned}
& \text { Carr's Index }=\frac{\text { Bulk density }- \text { Tapped density }}{\text { Bulk density }} \times 100------ \\
& ------------------(6) \\
& \text { Hausner's ratio }=\frac{\text { Bulk density }}{\text { Tapped density }}------------(7)
\end{aligned}
$$

\section{Particle size}

The particle size of the prepared microcapsules was measured by optical microscopy. Accurately weighed $50 \mathrm{mg}$ of the microcapsules of each batch were mounted on a micrometre slide and observed under a microscope to observe the particle size [27]. The particles size was obtained in terms of circulatory factor $(S)$, which can be calculated by using equation-8;

$$
\mathrm{S}=\frac{\mathrm{P} \times \mathrm{P}}{12.56 \times \mathrm{A}}
$$

Where, A is area $\left(\mathrm{cm}^{2}\right)$ and $\mathrm{P}$ is the perimeter of the circular tracing.

\section{Sphericity}

The particle shape (sphericity) was measured by calculating circulatory factor (S). The tracing obtained from the trainocular microscope was used to calculate area (A) and volume (V) [27]. This will indicate the approximate shape of the prepared microcapsules calculated by using equation-9;

$$
\operatorname{Sphericity~}(\phi s)=\frac{6 \mathrm{Vp}}{\mathrm{Dp} \times \mathrm{Ap}}------------(9)
$$

Where, Vp (volume of microcapsules) $=\pi d^{3} / 6$, Ap (area) $=\pi d^{2}=4 \pi r^{2}$ and Dp (diameter $)=\mathrm{d}$

\section{Swelling index}

The swelling index was determined by keeping the prepared microcapsules in phosphate buffer $(\mathrm{pH}$ 6.8) solution for $24 \mathrm{~h}$. After overnight wetting, the swollen microcapsules were collected, and their weight was noted. From the weight of the microcapsules before and after wetting, the swelling index was calculated by following equation-10 [27].

$$
S_{w}=\frac{W_{t}-W_{o}}{W_{o}} \times 100
$$

Where, $S_{w}=$ Percentage of swelling of microcapsules, $W_{t}=$ Weight of the microcapsules at time $t, W_{o}=$ Initial weight of the microcapsules.

\section{In vitro drug release study}

The prepared microcapsules were evaluated for drug release with the aid of a dissolution apparatus, USP Type-I (Electrolab TDT-06P Mumbai, India). Phosphate buffer ( $\mathrm{pH}$ 6.8) was used as the dissolution media and the apparatus was set to maintain $37 \pm 0.5$ ${ }^{\circ} \mathrm{C}$ temperature with a rotational speed of $50 \mathrm{rpm}$. Once the study started an aliquot of $5 \mathrm{ml}$ samples were withdrawn at specified time intervals $(0,1,2,3,4,6,8,10$ and $12 \mathrm{~h})$. Every time soon after the sample withdrawal, an equal amount of fresh medium was replaced to maintain the sink condition. The samples were filtered through a membrane filter $(0.45 \mu \mathrm{m})$ before subjecting to spectrophotometric quantitation. The drug concentration for all the samples was calculated on the basis of the UV absorbance and the cumulative percentage drug release versus time was plotted to compare the in vitro drug release from the selected microcapsule formulations [28].

\section{Fourier-transformed infrared (FT-IR) spectroscopy}

Possible drug-polymers interactions, if any were characterised by FT-IR spectroscopy (Shimadzu, Tokyo, Japan). The FT-IR spectra were obtained for the pure drug, a physical mixture of the drug with selected polymers and optimised microcapsules employing $\mathrm{KBr}$ pellet technique [29].

\section{Differential scanning calorimetry (DSC)}

The drug-polymers compatibility study at elevated temperature was also performed in a DSC apparatus (Shimadzu DSC 60, Tokyo, Japan). DSC thermo grams were obtained for the pure drug, a physical mixture of the drug with the selected polymers and optimised microcapsules. During DSC study, samples were heated in a nitrogen atmosphere (flow rate, $20 \mathrm{ml} \mathrm{min}^{-1}$ ) from $30-300{ }^{\circ} \mathrm{C}$ at a heating rate of $10 \mathrm{~min}^{-1}[30]$.

\section{Scanning electron microscopy (SEM)}

The surface picture of the optimised microcapsules was captured to study their surface morphology and shape employing SEM (Joel Scanning Microscope JSM-5800, Denton, USA). The dried microcapsules were mounted on brass stub using carbon paste and subjected to gold coating to make the surface electrostatic and kept in a desiccator. The stub was mounted on the sample holder tray in the electron microscope, and the acceleration voltage of $20 \mathrm{kv}$ was used with secondary electron image as the detector to observe the surface picture of the microcapsules [31].

\section{In vivo pharmacodynamics studies}

The in vivo study protocol was designed as per the guidelines of CPCSEA and permitted by the Institutional Ethical Committee, Roland Institute of Pharmaceutical Sciences, Berhampur under the protocol number RIPS/IAEC/46/2011. Eighteen male Wistar rats (200-250 gm) of either sex, equally divided into three groups (Group A, B and C) were taken for the in vivo antihypertensive activity. Each group of animals was accommodated in individual polypropylene cages (six per cage) under standard laboratory conditions, at $25 \pm 2 \mathrm{C}$ temperature and $55 \pm 5 \% \mathrm{RH}$ with water ad libitum and standard diet (Lipton feed, Mumbai, India). Before commencement of the study, to moderate the instinctive variations in blood pressure (BP), animals were acquainted with the experimental cage by bringing them into the restraining cage 3-4 times a day for a period of 30 min. After attaining at the normal condition the initial systolic BP of normotensive animals were recorded using the tail-cuff technique (noninvasive) based small animal tailblood pressure system, (NIBP200A, Biopac System Inc., California, USA). In the subsequent step of the study, induction of hypertension in all the 3 groups of animals was performed by subcutaneous injection of methylprednisolone acetate (MPA) (20 mg/kg/week) for $2 \mathrm{w}$ [32]. After induction of hypertension, the animals in the Group A were treated as control where no treatment was given. However, the animals in Group B and Group C were considered as treatment groups were given oral suspension of pure drug and optimised microcapsule formulation, each equivalent to $20 \mathrm{mg}$ of ramipril respectively. The mean systolic BP of animals was recorded after treatment at predetermined time intervals $(0,0.25,0.5,1,2,4,6,8$, and $12 \mathrm{~h}$ ). A plot was made between mean systolic BP (mm of $\mathrm{Hg}$ ) with respect to time (h). The results were statistically compared applying paired t-test to identify the considerable difference between the groups.

\section{Stability study}

The stability studies of the optimised microcapsules were carried out as per the ICH guidelines. The optimised formulation were suitably packed in the high-density plastic bottles and stored at 40 $\% / 75 \%$ RH for 3 mo in the stability chamber. The microcapsules were assessed for physiochemical properties, in vitro drug release and drug content at stated time periods $(0,1,2$ and $3 \mathrm{mo})$ to assess the stability [31].

\section{RESULTS AND DISCUSSION}

From the Taguchi screening design, the solutions with most influential factors affecting the response variables were revealed in pareto chart (fig. 1 and 2). The coefficients of linear polynomial equations generated for each of the response variables were used to screen out the factors. The influence of each of the factors studied on 
the response variables is depicted pictographically in fig. 3 to 6 respectively. The selected factors were subjected for optimisation with the help of BBD [16]. A total of 13 experimental runs were prepared and characterised for the selected response variables, which are represented in table 3 . The model was analysed for fitting into an appropriate mathematical model, i.e., quadratic model to obtain the curvature unveiling interaction effects among the variables. Further, the model was evaluated statistically for ANOVA and lack of fit, which showed that all the model terms were significant $(\mathrm{p}<0.05)$ with the insignificant lack of fit indicated that the model was best fitted. Screening of influential variables and optimisation of the formulation by design expert. The second polynomial coefficients generated for the studied response variables viz. drug release (\%), mucoadhesion (\%), drug entrapment
(\%) and particle size $(\mu \mathrm{m})$. The mathematical model generated for each response was found to be quite significant statistically $(p<0.05)$. The coefficients of four polynomial terms representing the concentrations of the chosen polymers, Na alginate (mg), HPMC $\mathrm{K} 100 \mathrm{M}(\mathrm{mg})$ and cross-linking time (h) and conc. $\mathrm{CaCl}_{2}(\% \mathrm{w} / \mathrm{v})$, respectively (i.e., $\beta 1$ to $\beta 4$ ) were found to be statistically significant for the studied response variables. Fig. 1 and 2 showed Pareto chart presenting the influence of each factor on various response variables individually. The results obtained from preliminary formulation studies indicated the levels of Na-alginate and HPMC K100M, crosslinking time (h) and conc. $\mathrm{CaCl}_{2}(\% \mathrm{w} / \mathrm{v})$ as 400,1000 and $1600 \mathrm{mg}$, 100,250 and $400 \mathrm{mg}, 3,4.5$ and $6 \mathrm{~h}$ and 5,10 and 15\%w/v for low (-), nominal (0) and high (+) levels respectively (table 3 ).

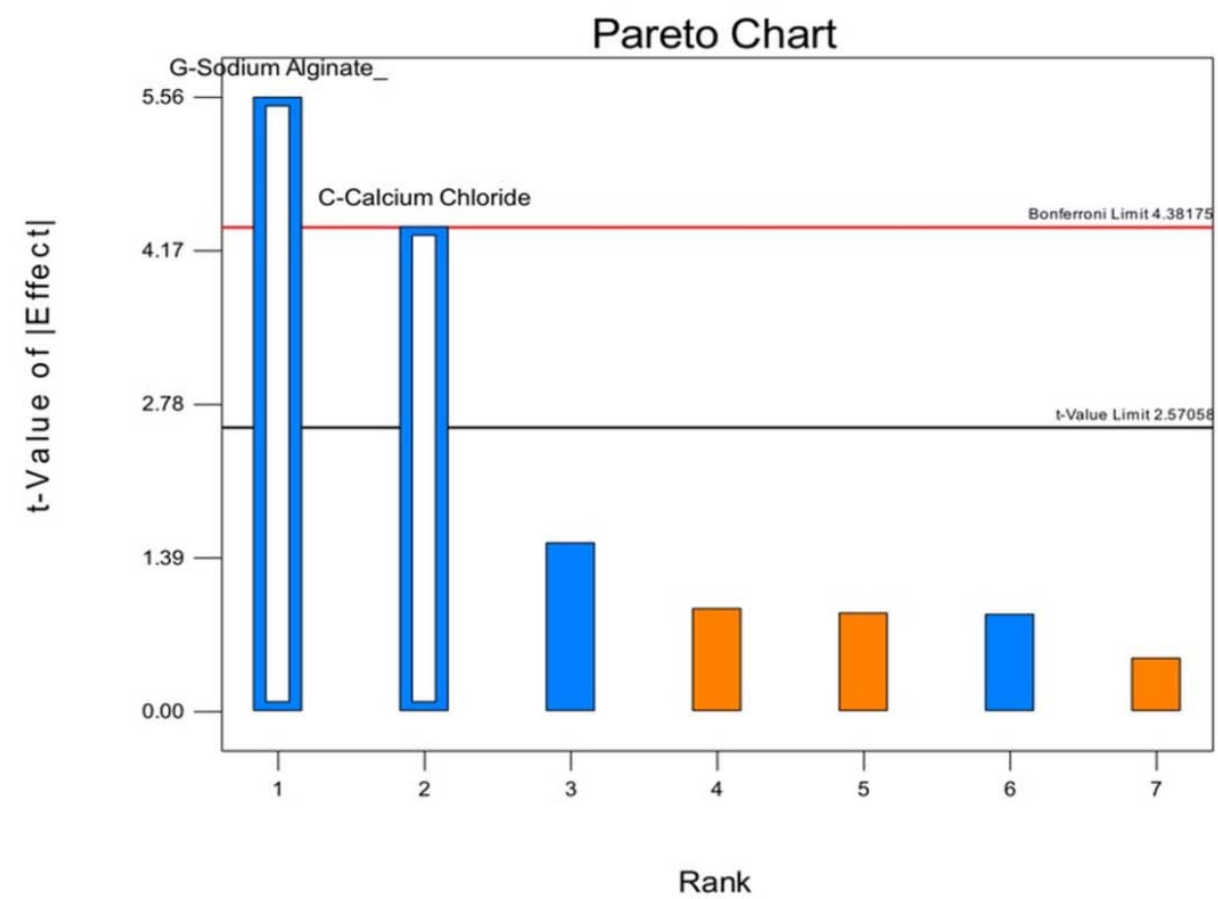

Fig. 1: Pareto chart depicting the effects of sodium alginate and calcium chloride factors on studied response variables

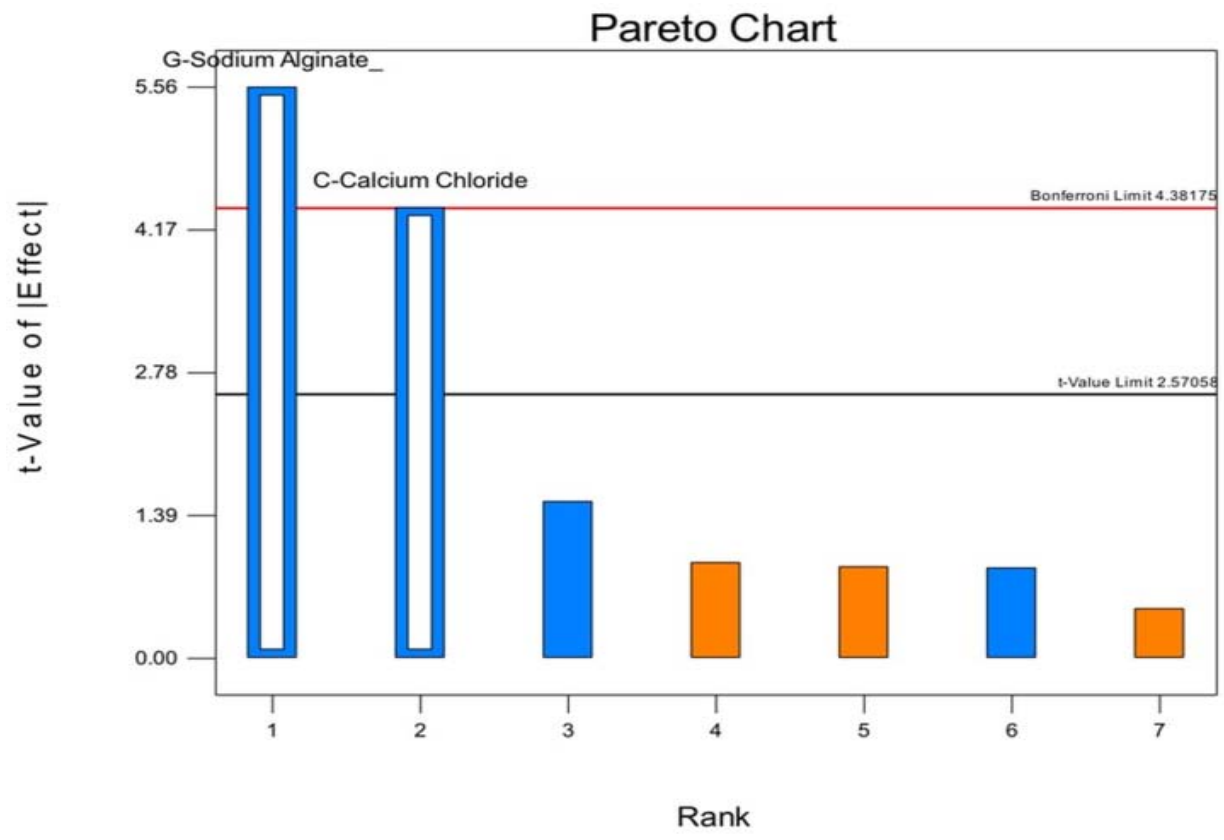

Fig. 2: Pareto chart depicting the effects of HPMC K100M, cross-linking time and sodium alginate factors on studied response variables 


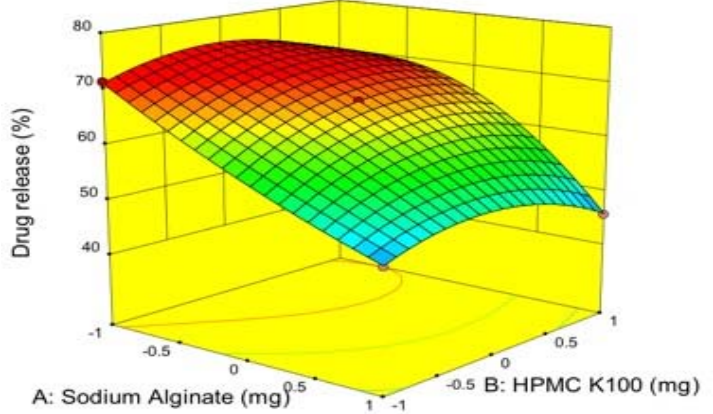

[A]

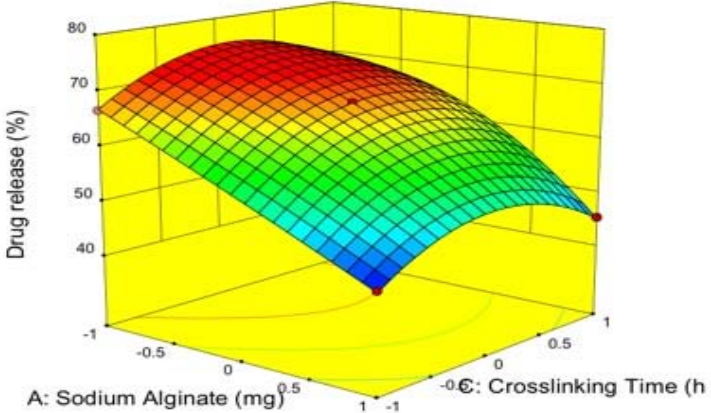

[B]

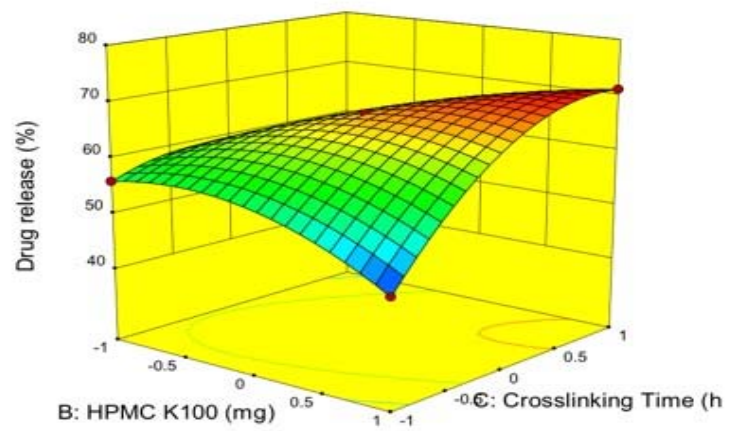

[C]

Fig. 3: 3D graph shows the effect of sodium alginate and HPMC K100M on percentage in vitro drug release [A]; sodium alginate and crosslinking time on in vitro drug release [B] and HPMC K100M and cross-linking time on in vitro drug release for the prepared mucoadhesive microcapsules [C]

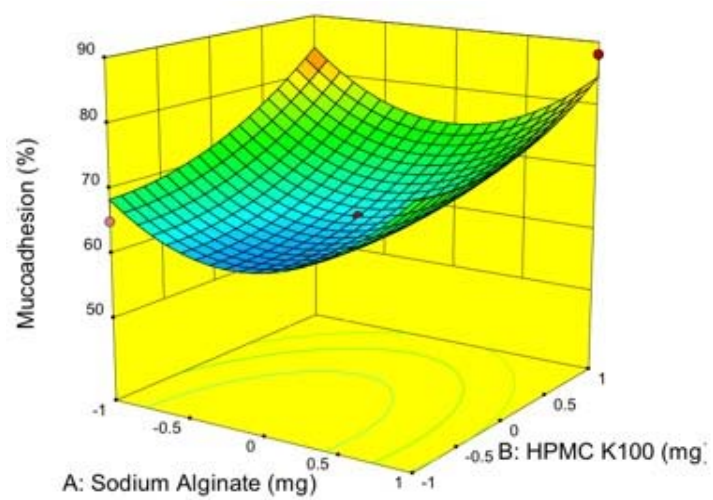

[A]

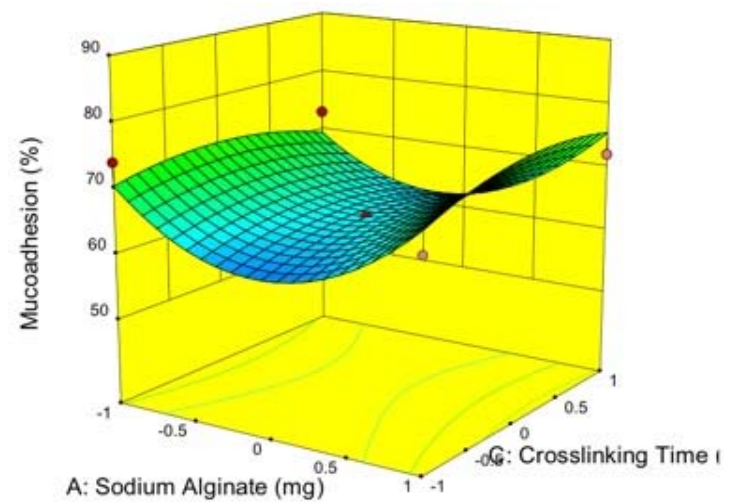

[B]

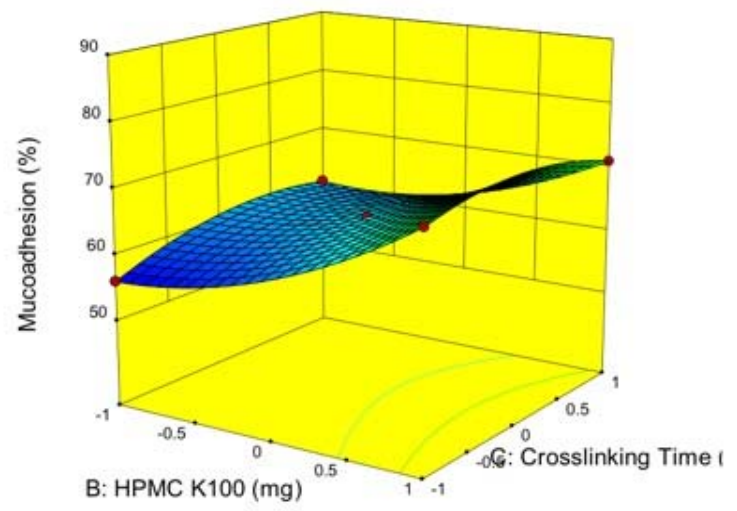

[C]

Fig. 4: 3D graph shows the effect of sodium alginate and HPMC K100M on percentage mucoadhesion [A]; sodium alginate and crosslinking time on percentage mucoadhesion [B] and HPMC K100M and cross-linking time on percentage mucoadhesion for the prepared mucoadhesive microcapsules [C] 


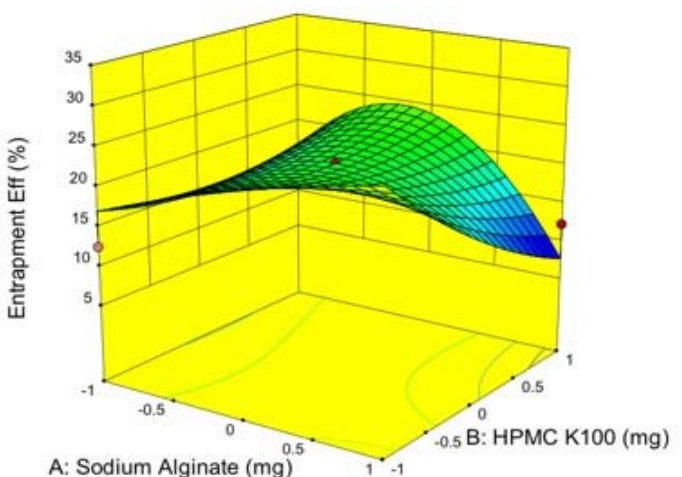

[A]

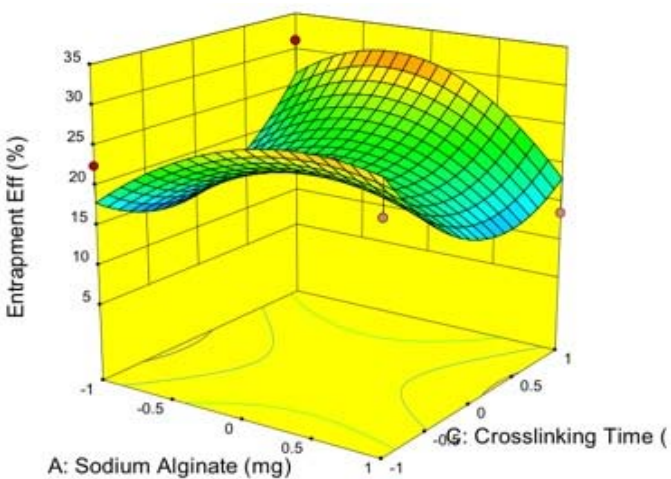

$[B]$

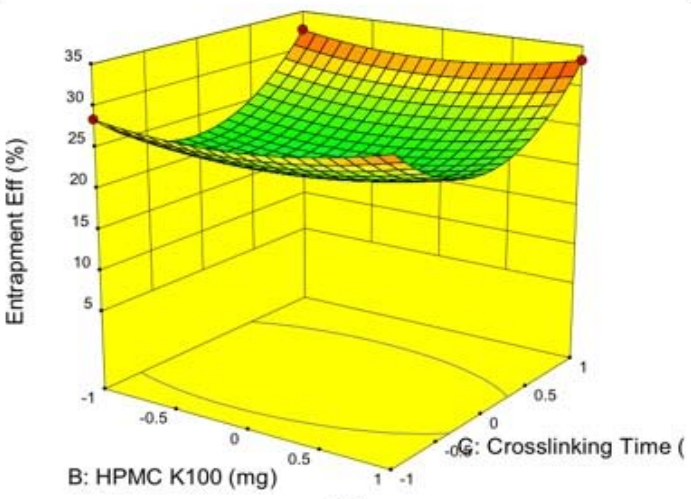

[C]

Fig. 5: 3D graph shows the effect of sodium alginate and HPMC K100M on entrapment efficiency [A]; sodium alginate and cross-linking time on entrapment efficiency $[B]$ and HPMC K100M and cross-linking time on entrapment efficiency for the prepared mucoadhesive microcapsules [C]

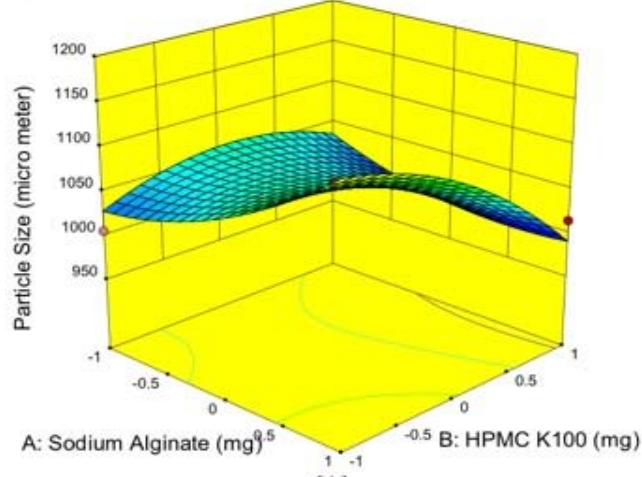

[A]

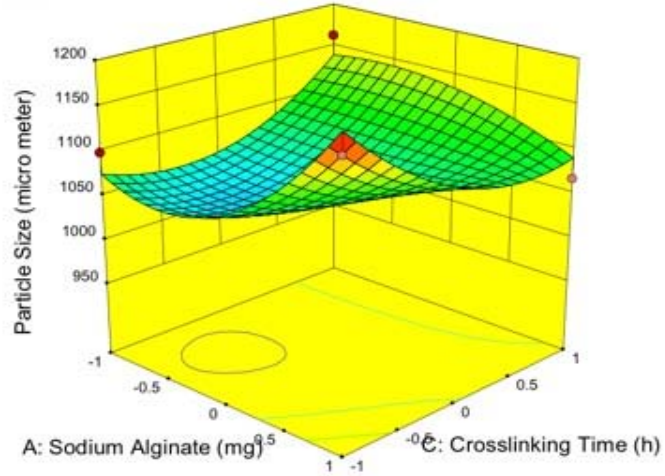

[B]

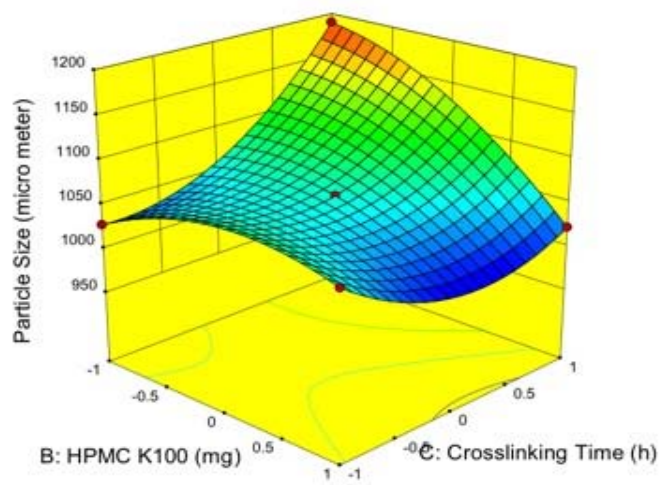

[C]

Fig. 6: 3D graph shows the effect of sodium alginate and HPMC K100M on particle size [A]; sodium alginate and cross-linking time on particle size [B] and HPMC K100M and cross-linking time on particle size for the prepared mucoadhesive microcapsules [C] 


\section{Systematic optimisation of formulations and data analysis}

BBD is employed to determine the critical conditions for optimising the desirability criteria of more sustained release, yielded maximum entrapment efficiency, maximum mucoadhesion, and required particle size of the formulation. Responses for all the 13 experimental runs were determined and their mathematical relationships with the variables measured in the form of polynomial equations. The calculated independent and interaction effects of process variables (X1, X2, X3 and X4) on the responses (Y1, Y2, Y3 and Y4). The coefficient values in the polynomial equation represent the effects of the corresponding variable for a particular response. A negative sign of the coefficient represents antagonistic effect; whilst positive sign indicates a synergistic effect of the variables. Threedimensional (3D) response surface plots (fig. 3 to 8) were formed to identify the significance of the polynomial model through graphical visual interpretation. These plots are valuable to assess the relationship of two factors and their interactions with the response while keeping the other factors constant. Fig. 3 exhibits a gradual decrease in drug release (Y1) with increasing concentration of sodium alginate (X1), while drug release was increased with increasing concentration of HPMC K100M (X2). Similarly, fig. 4 showed that with an increase in X1 concentration (400 to1600 mg), mucoadhesion (Y2) was reduced. However, with elevated concentration of $\mathrm{X} 2$ revealed a significant increase in mucoadhesion.

This indicated that HPMC K100M has more significant effect on mucoadhesion property of the microcapsules, while sodium alginate has less effect on mucoadhesion. In fig. 5, the \% drug entrapment (Y3) decreases as the concentration of X2 gradually increased while the concentration of X1 has a significant effect on drug entrapment efficiency.

Therefore, sodium alginate has a major role on drug entrapment. The plot in fig. 6 showed that particle size (Y4) varies in a linearly descending order with increased concentration of X2, while the concentration of $\mathrm{X} 1$ has no significant effect on it. At last the design was suggested that cross-linking time (X3) and concentration of $\mathrm{CaCl}_{2}$ (X4) has no significant role on all the responses (Y1-Y4). Hence both were taken as null factors in all the experiments [14-17].
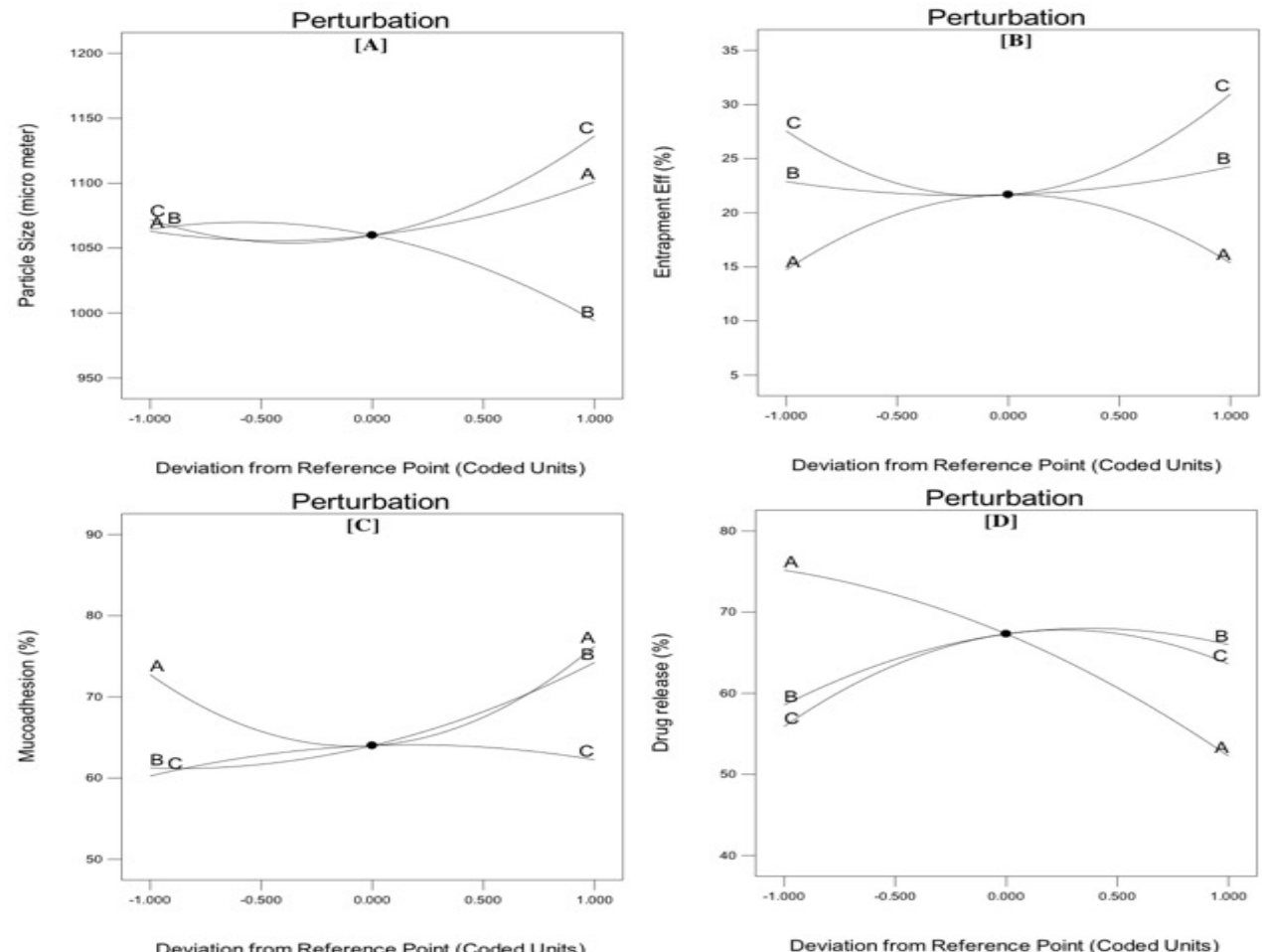

Fig. 7: Pertubation plots showing for actual factors on responses such as particle size $(\mu \mathrm{m})[\mathrm{A}]$; entrapment efficiency $(\%)$ $[B]$; mucoadhesion $(\%)[C]$ and percentage in vitro drug release [D]

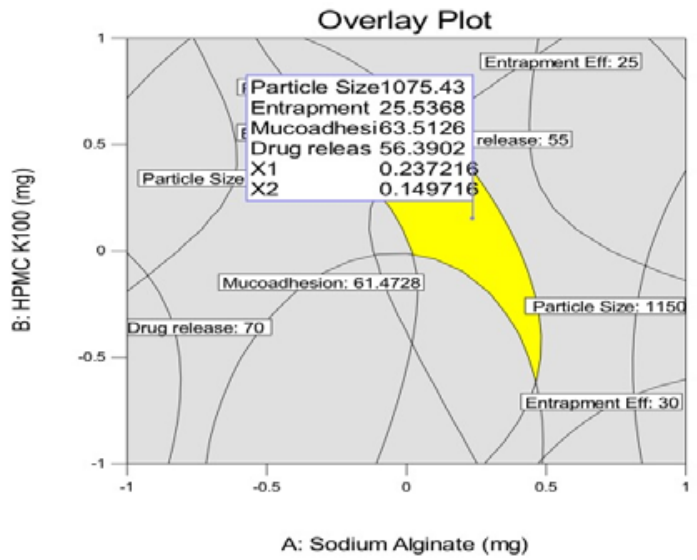


Fig. 8: Overlay plot of factors X1 (sodium alginate) and X2 (HPMC K100M) on responses such as particle size, percentage of drug entrapment efficiency, percentage of mucoadhesion and percentage in vitro drug release

\section{Characterization}

\section{Production yield}

The yield of production was not so good for all formulation. The most probable reason for its low percentage (\%) yield is that there is wastage of formulation ingredients during the preparation process [21]. Yield value of selected formulations was found to be 33.65 to 48.35 as shown in table 4.

\section{Drug content and drug entrapment efficiency}

Drug content range from 55.87 to 93.86 and drug entrapment efficiency from 51.39 to 69.73 respectively as shown in table 4 [21].

\section{Loose surface crystal study}

The loose surface crystal study was executed for all the formulations and the results obtained are depicted in table 4 . From the study, an initial discharge of ejected medication from the microcapsules surface (formulation F1 to F6) was observed in the range of
39.99 to 45.95 [23]. In vitro wash-off test (table 4 and fig. 9) summarised the result of mucoadhesive strength or \% mucoadhesion in goat intestine mucosa for all the formulations. The adhesion time of microcapsules followed the rank order $\mathrm{F} 4>\mathrm{F} 5>\mathrm{F} 3>\mathrm{F} 2>\mathrm{F} 6>\mathrm{F} 1$. Results indicated that the viscosity of the polymer was strongly associated with the adhesion. Viscosity was directly proportional to the mucoadhesive property. Unlike others, the microcapsules formulated with sodium alginate as one of the ingredients unveiled superior mucoadhesive property as in the case of in vitro wash-off test. A quicker wash off was observed in phosphate buffer ( $\mathrm{pH}$ 6.8), since $\mathrm{pH}$ of the medium governs the hydration, solubility and mucoadhesive of the polymers. Ionisation of carboxylic acid or other functional groups on the polymers may be one of the reasons for increased solubility and reduced adhesive strength that attributes to rapid wash off. The results of the wash-off test specified that formulation F4 showed maximum mucoadhesion. This might be due to high molecular weight, linear, unbranched structure and viscosity of HPMC K100M as on enhancing agent in selected medium [24].

Table 4: Production yield (\%), drug content (\%), entrapment efficiency (\%), loose surface crystal study, moisture loss (\%), particle size $(\mu \mathrm{m})$, mucoadhesion $(\%)$, sphericity and swelling index of selected runs

\begin{tabular}{|c|c|c|c|c|c|c|c|c|c|}
\hline $\begin{array}{l}\text { Formul- } \\
\text { ation } \\
\text { code }\end{array}$ & $\begin{array}{l}\text { Production } \\
\text { yield* } \\
(\% \pm S D)\end{array}$ & $\begin{array}{l}\text { Drug } \\
\text { content* } \\
(\% \pm S D)\end{array}$ & $\begin{array}{l}\text { Entrapmen } \\
\text { t efficiency* } \\
(\% \pm S D)\end{array}$ & $\begin{array}{l}\text { Loose } \\
\text { surface } \\
\text { crystal } \\
\text { study* } \\
\text { (\% } \pm \text { SD) }\end{array}$ & $\begin{array}{l}\text { Percentage } \\
\text { moisture } \\
\text { loss after } \\
24 h^{*} \\
(\% \pm S D)\end{array}$ & $\begin{array}{l}\text { Particle size* } \\
(\mu \mathrm{m})\end{array}$ & $\begin{array}{l}\text { Percentage } \\
\text { Mucoadhe- } \\
\text { sion after } 6 \\
\text { h* }\end{array}$ & $\begin{array}{l}\text { Sphericity* } \\
\text { (S) }(\% \pm S D)\end{array}$ & $\begin{array}{l}\text { Swellin } \\
\text { g index } \\
\text { after } \\
24 h^{*}\end{array}$ \\
\hline F1 & $33.65 \pm 0.02$ & $55.87 \pm 0.01$ & $58.28 \pm 0.02$ & $45.95 \pm 0.03$ & 5.26 & $670 \pm 0.03$ & 17 & $0.59 \pm 0.23$ & 73 \\
\hline F2 & $48.35 \pm 0.03$ & $60.93 \pm 0.02$ & $69.73 \pm 0.03$ & $44.20 \pm 0.03$ & 5.26 & $242.5 \pm 0.01$ & 20 & $1.0 \pm 0.21$ & 80 \\
\hline F3 & $44.51 \pm 0.04$ & $70.26 \pm 0.03$ & $51.39 \pm 0.04$ & $39.99 \pm 0.02$ & 0 & $432.4 \pm 0.02$ & 22 & $1.0 \pm 0.23$ & 88 \\
\hline F4 & $47.45 \pm 0.05$ & $68.43 \pm 0.04$ & $56.14 \pm 0.01$ & $41.95 \pm 0.04$ & 5.26 & $540 \pm 0.04$ & 30 & $1.0 \pm 0.13$ & 90 \\
\hline F5 & $45.36 \pm 0.05$ & $81.23 \pm 0.05$ & $66.49 \pm 0.02$ & $37.73 \pm 0.02$ & 0 & $642.5 \pm 0.03$ & 24 & $1.0 \pm 0.14$ & 82 \\
\hline F6 & $41.87 \pm 0.01$ & $93.86 \pm 0.06$ & $59.87 \pm 0.03$ & $35.08 \pm 0.01$ & 11.23 & $1007.5 \pm 0.02$ & 20 & $1.0 \pm 0.15$ & 76 \\
\hline
\end{tabular}

*Each reading is an average of three determinations (mean $\pm S$. $D(n=3) n=$ no. of observation

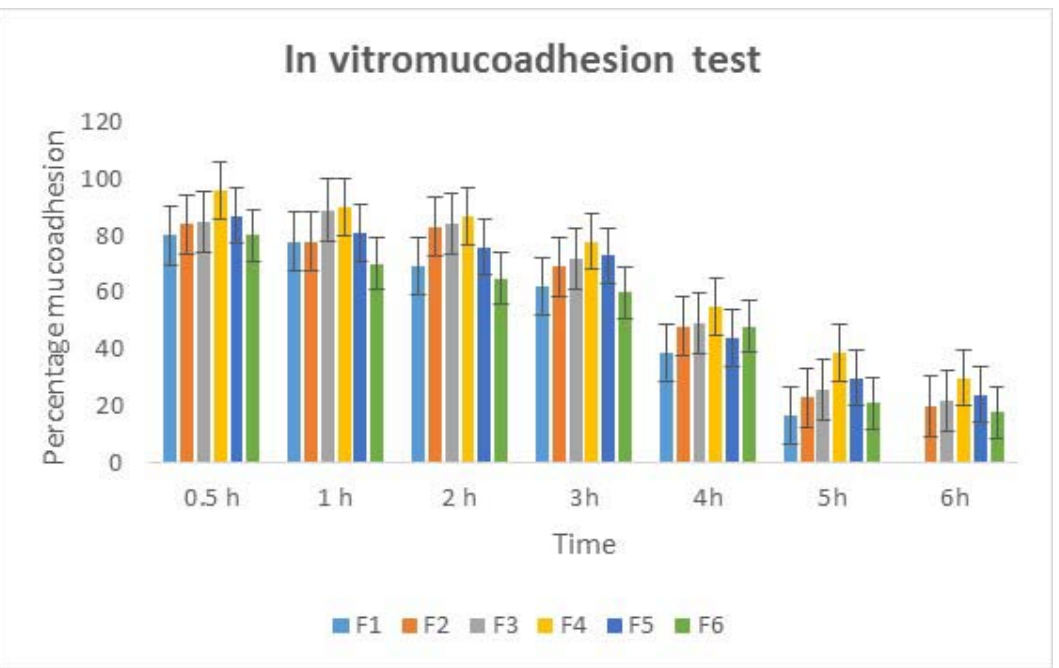

Fig. 9: Percentage of mucoadhesion of selected formulations after $6 \mathrm{~h}$, each reading is an average of three determinations (mean \pm SD ( $=3$ ) n=no. of observation

\section{Percentage moisture loss}

The percentage moisture loss was found to be in the range of 5.26 to 11.23 for the formulation F1 to F6 as summarised in table 4 . Percentage moisture loss increases with respect to time [25].

\section{Micromeritics properties}

One of the important factors affecting flowability of ramipril was interparticle friction. Microcapsules show the desired flowability due to the optimal presence of moisture; spherical shape and diminished cohesiveness. The flow properties of microcapsules such as angle of repose, Hausner's ratio and Carr's Index are depicted in table 5 [26]. The pure drug shows the angle of repose of 36.29 and exhibited poor flow, whereas the angle of repose of six selected formulations showed excellent flowability and ranged from 15.52 to 22.20 . The carr's index of six selected formulations exhibited excellent flow properties and ranged from 8.42 to 14.65 as compared to the pure drug, which was 
25.69 indicating poor flowability before formulating to microcapsules. Hausner's ratio of the pure drug was 2.36 , which indicated poor flowability, but the formulated microcapsules exhibited good flow properties that ranged from 1.04 to 1.3 .

Table 5: Micromeritics data of pure drug and selected formulations

\begin{tabular}{llll}
\hline Formulation code & Angle of repose $\left(^{\circ}\right)^{*}$ & Carr's index $^{*}$ & Hausner's ratio* $^{*}$ \\
\hline F0 (Pure drug) & $36.29 \pm 0.32$ & $25.69 \pm 0.45$ & $2.36 \pm 0.44$ \\
F1 & $16.20 \pm 0.28$ & $12.45 \pm 0.41$ & $1.1 \pm 0.39$ \\
F2 & $15.52 \pm 0.45$ & $13.23 \pm 0.33$ & $1.02 \pm 0.34$ \\
F3 & $20.30 \pm 0.51$ & $8.42 \pm 0.44$ & $1.04 \pm 0.44$ \\
F4 & $16.25 \pm 0.44$ & $14.65 \pm 0.45$ & $1.02 \pm 0.34$ \\
F5 & $18.12 \pm 0.38$ & $12.26 \pm 0.44$ & $1.01 \pm 0.51$ \\
F6 & $22.20 \pm 0.29$ & $10.12 \pm 0.38$ & $1.3 \pm 0.44$ \\
\hline
\end{tabular}

*Each reading is an average of three determinations (mean $\pm S D)(n=3) n=$ no of observation

\section{Particle size analysis}

The optical microscopic study of particle size distribution revealed that the microcapsules are uniform in size in each formulation with average diameter ranged from $242.5 \pm 0.01$ to $1007.5 \pm 0.02 \mu \mathrm{m}$, which is more arbitrarily falls within the particle size range of $10-1000 \mu \mathrm{m}$ (table 4 ). This may be due to the particle size is directly proportional to viscosity, where an increase in the viscosity upturns the droplet size.

Hence, adequate viscosity has to be maintained which in turn not only influence the particle size but also affect the mucoadhesive strength of the formulation. The significance difference in particle size for different polymers with different viscosity grade and different mucoadhesive strength was evaluated applying one-way ANOVA without replication at $\mathrm{P}<0.001$ level [27].

\section{Sphericity}

The sphericity of all formulations from F1 to F6 ranged from $0.59 \pm 0.23$ to $1.0 \pm 0.23$ as shown in table 4 . The ramipril-loaded microcapsules obtained had a circulatory factor very close to 1.00 confirming their sphericity. Overall all the formulations were spherical in appearance. Further, the optimised formulation was confirmed by SEM study [27].

\section{Swelling index}

In the presence of water, swelling varies with polymer ionic strength and concentration. Table 4 shows \% swelling index of different formulations at specified time intervals. The study unveiled rapid swelling of all the formulations after submerged in phosphate buffer $(\mathrm{pH}$ 6.8). However, this behaviour greatly affects the adhesive and cohesive properties of the polymers.

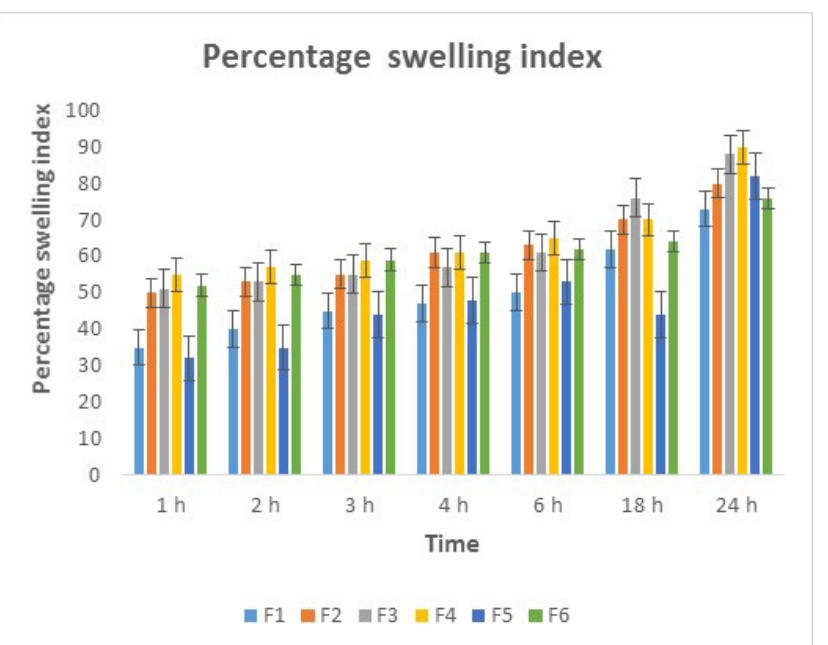

Fig. 10: Swelling index of selected formulations after $24 \mathrm{~h}$, each reading is an average of three determinations (mean $\pm S$. D $(n=3)$ n=no. of observation
Mucoadhesive microcapsules are expected to possess considerably stronger adhesion due to more water uptake from the underlying mucosal tissue by absorbing, swelling and capillary effects. From the calculated data, the swelling index for the formulations were found to be in the range of $\mathrm{F} 4>\mathrm{F} 3>\mathrm{F} 5>\mathrm{F} 2>\mathrm{F} 6>\mathrm{F} 1$ (fig. 10). After 24h, HPMC K100M showed highest swelling (90\%) for formulation F4.

The reason behind to show maximum swelling behaviour is due to (i) its viscosity by forming a swellable gel or (ii) its high ionisation at pH6.8 and (iii) higher water uptake capacity.

\section{In vitro drug release study}

The in vitro drug release studies of ramipril were initially performed in $0 . \mathrm{N} \mathrm{HCl}$ for $2 \mathrm{~h}$ followed by phosphate buffer $\mathrm{pH}$ 6.8) for $22 \mathrm{~h}$. The microcapsules prepared with sodium alginate, and HPMC K100M were exposed to the dissolution medium and amount of drug released in the acidic medium $(0.1 \mathrm{~N} \mathrm{HCl})$ for $2 \mathrm{~h}$ was determined. Retardation of drug release was observed in case phosphate buffer pH 6.8. Sodium alginate-based microcapsules not significantly retarded the drug released at the examined time points over a period up to $24 \mathrm{~h}$. The release of ramipril was mainly driven by permeation of drug through the hydrophobic polymer membrane. An initial burst effect was seen by all the formulations, which was attributed to the drug present on the surface of the microcapsules as also inferred from loose surface crystal study. Diffusion controlled system is the approach to control the drug release as the drug can travel through the pores formed during surface hardening (fig. 11).

The release profiles often comprise two main expulsion processes, (i) initial burst of expelled medication from the surface of the sphere to confirm initial plasma drug concentration and (ii) usually more constant stage with release rates dependent on diffusion and degradation of the drug from the inner layer of the dosage form. Therefore, the diffusional distance between the initial drug locations inside the formulation affects the release profile. Owing to its water-insoluble and low permeability properties, sodium alginate is a widely accepted sustained release matrix. However, varying the concentration of HPMC K100M, which forms hydrophilic passages inside the microcapsules that helps the drug to diffuse out easily, can influence the drug release capability of sodium alginate. From the in vitro dissolution data and plotted it is seen that after $24 \mathrm{hr}$ study, formulation F4 showed better drug release retardation as compared to other formulations. The drug content in case of HPMC K100M is about $94 \%$ with good swelling as well as excellent mucoadhesion properties. The viscosity of the mucoadhesive polymer has a significant role in both bio-adhesion and sustained action.

\section{Kinetics of drug release}

To find out the mechanism of drug release, the in vitro release profiles were applied on various kinetic models. The release data was analysed according to the different kinetic equation to illustrate the kinetics of drug release from microcapsules (table 6). Release data of all the formulations displayed higher regression coefficient values in first order kinetics. 


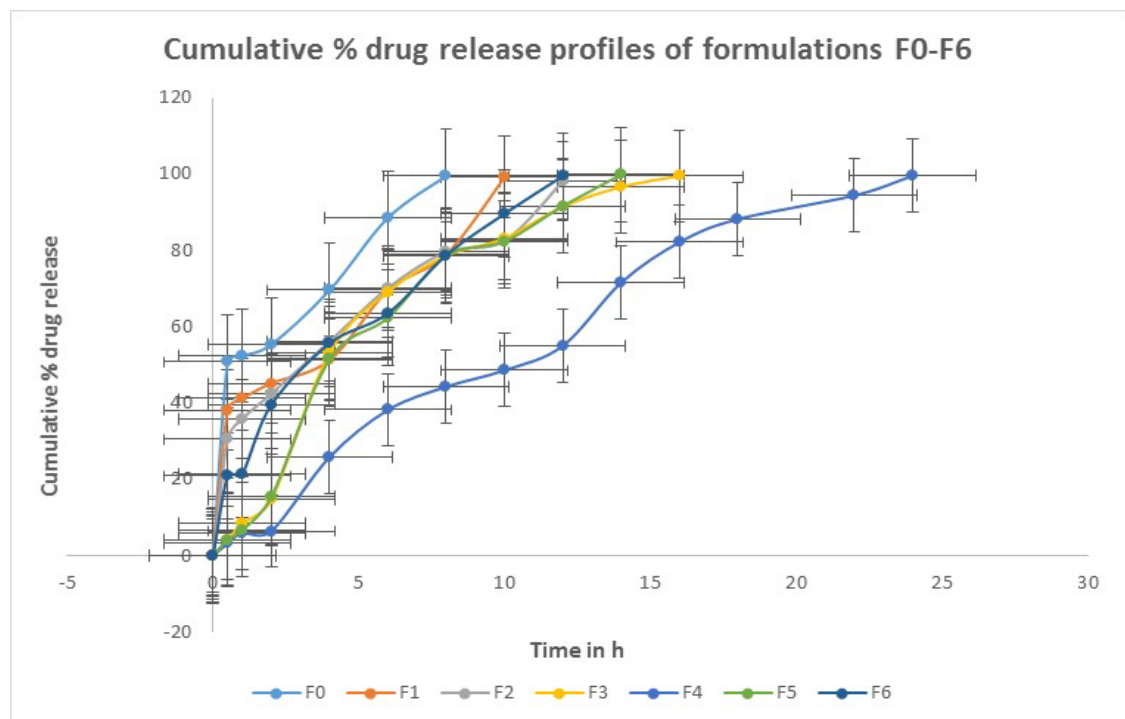

Fig. 11: Cumulative $\%$ drug release profiles of formulations F0-F6, Each reading is an average of three determinations (mean $\pm S D(n=3)$ n=no. of observation

The drug release is diffusion predominant as compared to other mechanisms, which indicates that release of the drug is dependent on polymer concentration. The data obtained were applied to Korsmeyer Peppa's model so as to find out the drug diffuse coefficient or release exponent (n). The n-value of microcapsules of different formulations ranged from 0.28 to 0.90 indicating that the drug released was diffusion controlled i.e. anomalous transport. It maybe happened because of a significant increase in osmotic pressure (driving forces), subsequent rapid relaxation and swelling of the polymer network Basing on the above discussion, it is observed that F4 is the optimised formulation keeping in view the parameters like in vitro wash off test, swelling index and sustained drug release.

Table 6: In vitro dissolution kinetics data of selected formulations

\begin{tabular}{|c|c|c|c|c|}
\hline Formulation code & $\begin{array}{l}\text { Zero } \\
\text { Order }\left(\mathbf{R}^{2}\right)\end{array}$ & $\begin{array}{l}\text { First } \\
\text { Order }\left(R^{2}\right)\end{array}$ & $\begin{array}{l}\text { Higuchi } \\
\left(\mathrm{R}^{2}\right)\end{array}$ & $\begin{array}{l}\text { Korsmeyer-Peppa's } \\
\text { model release exponent (n) }\end{array}$ \\
\hline F1 & 0.86 & 0.94 & 0.93 & 0.28 \\
\hline $\mathrm{F} 2$ & 0.89 & 0.90 & 0.88 & 0.31 \\
\hline F3 & 0.90 & 0.97 & 0.94 & 0.82 \\
\hline $\mathrm{F} 4$ & 0.97 & 0.96 & 0.92 & 0.90 \\
\hline F5 & 0.94 & 0.95 & 0.93 & 0.83 \\
\hline F6 & 0.94 & 0.99 & 0.94 & 0.48 \\
\hline
\end{tabular}

$\mathrm{R}^{2}$ : Regression correlation coefficient

\section{Drug-polymer interaction studies (FT-IR)}

From the FT-IR spectral analysis, no incompatibility was found between drug and polymers like sodium alginate, chitosan, carbopol 974P, HPMC K100M and sodium CMC. IR spectra of pure drug showing major peaks are compared with the physical mixture of the pure drug with a combination of sodium alginate and selected mucoadhesive polymer.

From the spectral comparison, neither a significant shift in the wave number of the major peaks nor a variation in the peaks intensity of drug was observed (fig. 12) confirming no interaction between the drug and mucoadhesive polymers. It shows that there was no alteration in the properties of the drug and polymers during the formulation. Hence the drug and polymers were compatible with each other [29].

\section{DSC}

In the case of pure drug and physical mixture shows a sharp peak at $208{ }^{\circ} \mathrm{C}$ which was observed due to melting, whereas, in the case of drug-loaded microcapsules, no such characteristic peak was observed at $208^{\circ} \mathrm{C}$, suggesting that drug is molecularly dispersed in the matrix (fig. 13) [30].

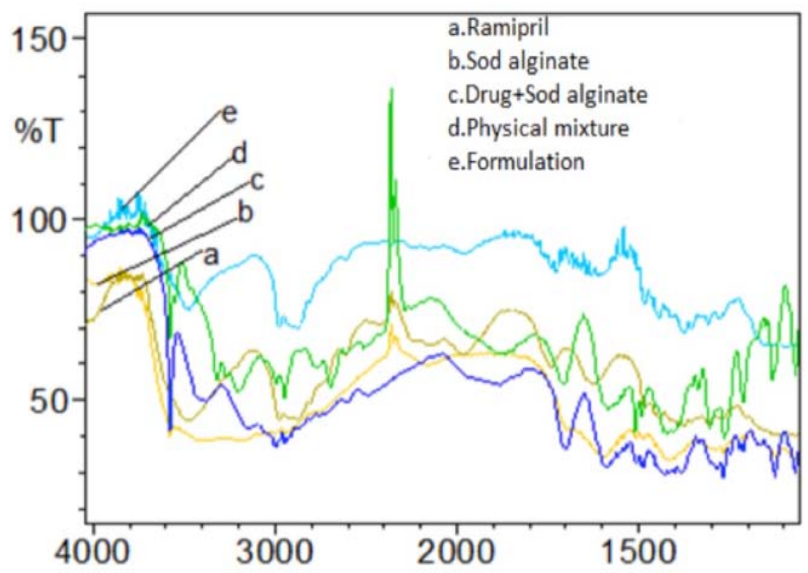

Fig. 12: FT-IR spectra of ramipril [a], sodium alginate [b], pure drug+sodium alginate+HPMC K100M (physical mixture) [c] and optimized mucoadhesive microcapsule formulation [d] 


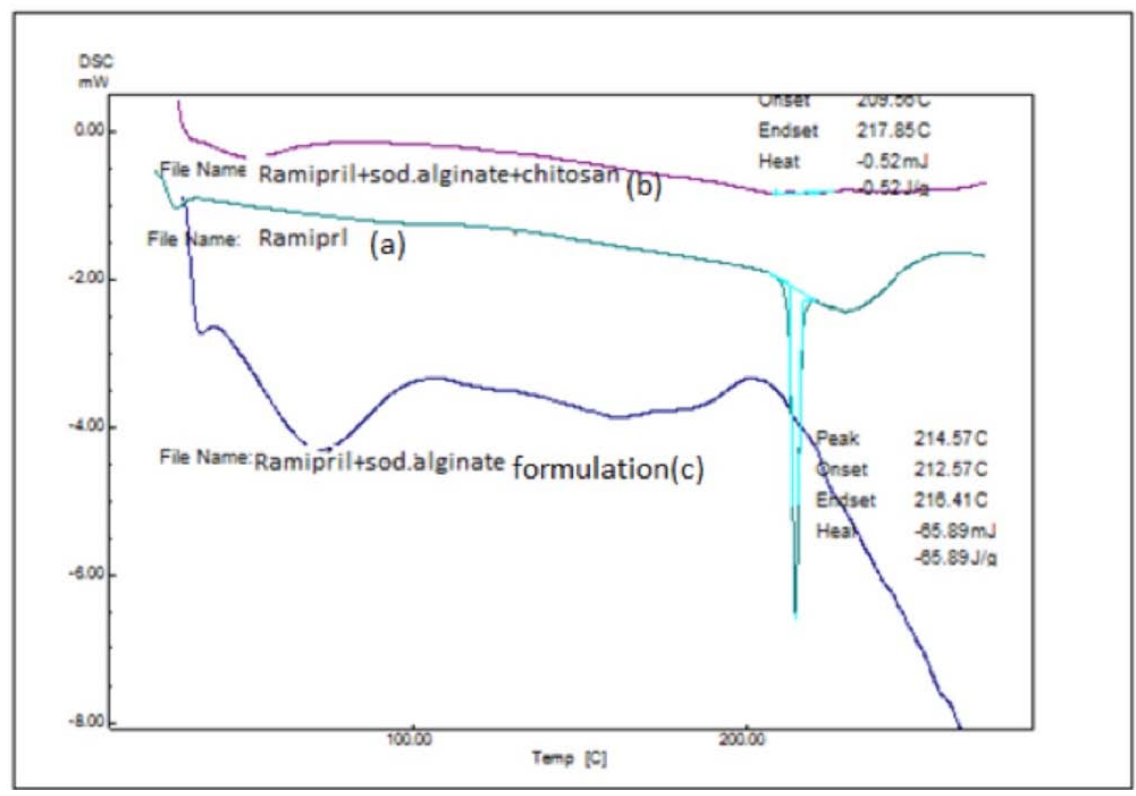

Fig. 13: DSC graphs of ramipril [a], optimized formulation [b] and pure drug+sodium alginate+HPMC K100M (physical mixture) [c]

\section{SEM}

From the SEM fig. it is seen that sodium alginate coated microcapsules are spherical morphology showing discrete, nonaggregated and cohesive types of texture (fig. 14) [31].

\section{Stability study}

Short-term stability studies as per ICH guidelines were carried out for the optimised formulation (F4). The drug content and cumulative $\%$ drug released were tabularized in table 7 . After 3 mo stability study, it was seen that at selective relative humidity with higher temperature optimised formulation are stable based on the obtained percentage drug content and percentage drug release data, hence the formulation was stable (fig. 15) [31]

\section{In vivo pharmacodynamic studies}

Fig. 16, represents the comparison of mean systolic BP of different groups of the animal after treatment with an oral suspension of pure drug and optimised formulation of ramipril. The comparison of mean systolic BP of rats before and after MPA treatment for $2 \mathrm{w}$ revealed induction of hypertension in the case of normotensive rats due to excessive production of glucocorticoids. Administration of MPA raised the mean BP to 192.36 to $218.23 \mathrm{~mm}$ of $\mathrm{Hg}$ in normotensive animals.

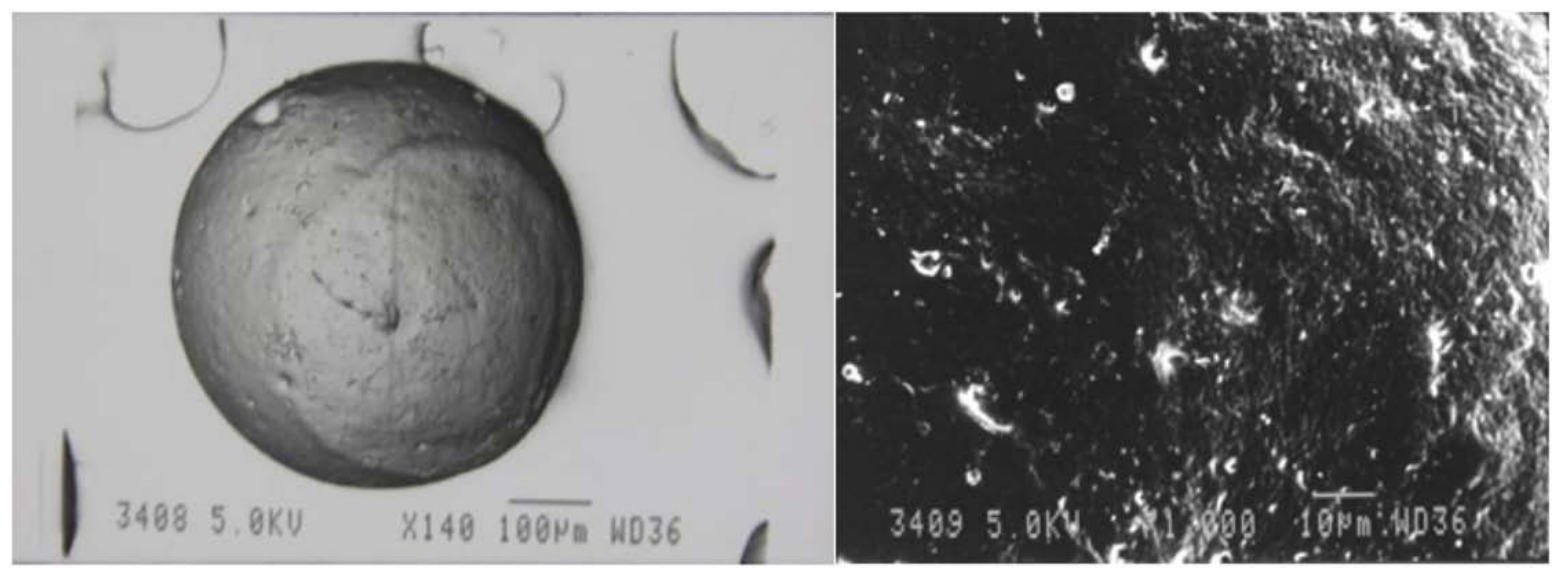

Fig. 14: SEM images of microcapsules of optimised mucoadhesive microcapsule formulation at lower magnification and higher magnification

Table 7: Stability data of optimised formulation before and after storage condition

\begin{tabular}{lllll}
\hline Formulation (Optimised) & Before stability & & After stability & \\
\hline F4 & Drug content (\%)* & Cum. \% drug release* & Drug content* & Cum. \%drug release* \\
& $68.43 \pm 0.04$ & $99.5143 \pm 0.01$ & $68.21 \pm 0.02$ & $99.2843 \pm 0.03$ \\
\hline
\end{tabular}

*Each reading is an average of three determinations (mean $\pm S$. $D(n=3) n=$ no. of observation 


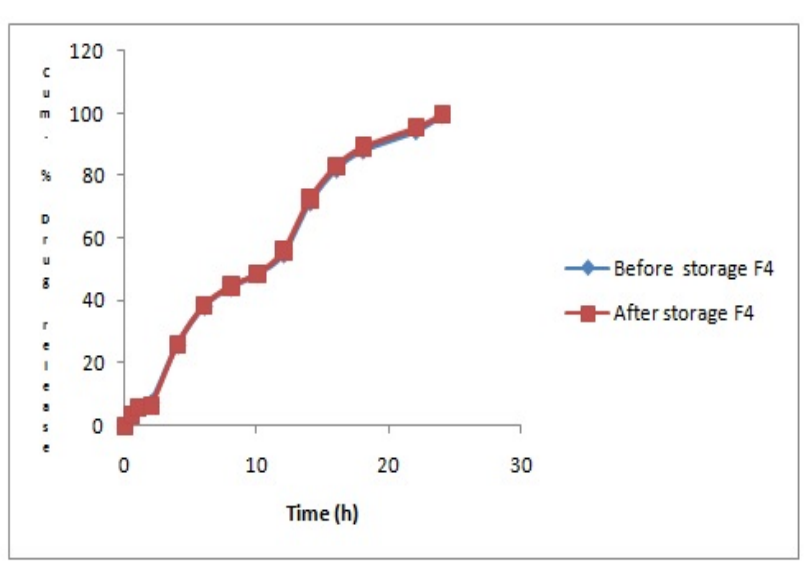

Fig. 15: Zero order plot of formulation F4 before and after stability of three months storage

Oral administration of ramipril suspension and optimised formulation revealed a significant decrease into mean systolic BP. Whereas in case of control group, mean systolic BP was constant throughout the study period with minimum BP was recorded to be $156.31 \mathrm{~mm}$ of $\mathrm{Hg}$ at $12 \mathrm{~h}$ (table 8), while in treatment group received the oral suspension of ramipril observed reduction of mean systolic BP to $153.41 \mathrm{~mm}$ of $\mathrm{Hg}$ after $0.5 \mathrm{~h}$ and $154.18 \mathrm{~mm}$ of $\mathrm{Hg}$ in $2 \mathrm{~h}$. However administration of the optimized formulation of ramipril observed a significant reduction in mean systolic BP to 112.16 of $\mathrm{Hg}$ after $0.5 \mathrm{~h}$ and $110.21 \mathrm{~mm}$ of $\mathrm{Hg}$ in 2 $h$ i.e., animals reach to normotensive state due to faster onset of action attributed by enhanced bioavailability potential of mucoadhesive formulations (fig. 16) [32].

Table 8: Comparison data of mean systolic BP of different groups of animal after treatment with oral suspension of pure drug and optimised formulations of ramipril

\begin{tabular}{llll}
\hline $\begin{array}{l}\text { Time } \\
\text { (h) }\end{array}$ & $\begin{array}{l}\text { Contro } \\
\text { l }\end{array}$ & $\begin{array}{l}\text { Oral suspension of } \\
\text { pure drug }\end{array}$ & $\begin{array}{l}\text { Optimized } \\
\text { formulation }\end{array}$ \\
\hline 0 & 218.23 & 202.46 & 192.36 \\
0.25 & 166.23 & 158.92 & 116.43 \\
0.5 & 162.58 & 153.41 & 112.16 \\
1 & 167.51 & 151.29 & 111.92 \\
2 & 164.29 & 154.18 & 110.21 \\
4 & 161.41 & 152.63 & 118.26 \\
6 & 158.26 & 149.56 & 111.26 \\
8 & 152.6 & 146.56 & 119.4 \\
12 & 156.31 & 140.69 & 112.23 \\
\hline
\end{tabular}

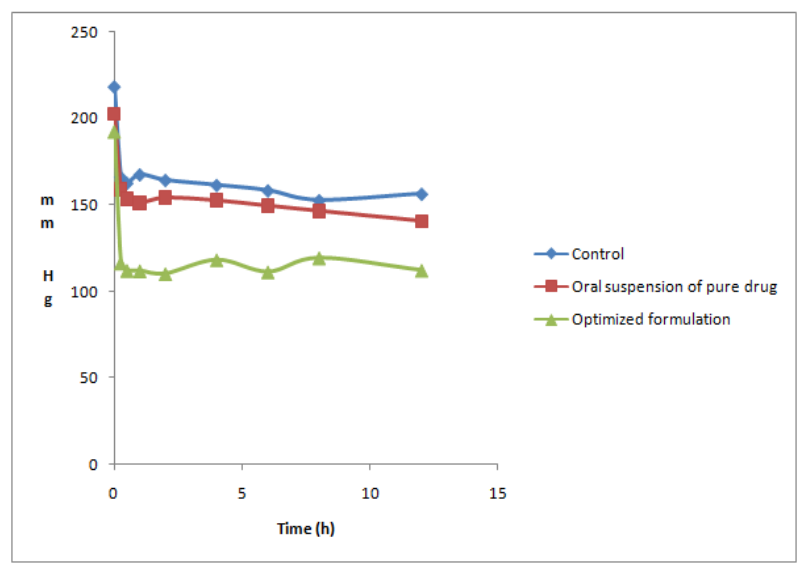

Fig. 16: Comparison of mean systolic BP of different groups of animal after treatment with oral suspension of pure drug and optimised formulations of ramipril

\section{CONCLUSION}

The present studies, therefore, shows the successful formulation of mucoadhesive microcapsules of ramipril by ionic gelation method using sodium alginate and HPMC K100M as suitable polymers. The application of experimental design methodology helped to prepare the optimised formulation, which showed good sustained release profile of drug release with enhanced mucoadhesion property and antihypertensive activity. The drug release was found to be polymer concentration dependent and followed first order kinetics. FTIR and DSC studies used for solid-state characterization confirmed the absence of any physiochemical interaction between drug and polymers. SEM analysis showed a smooth surface with the spherical appearance of microcapsules. Further, in vivo pharmacodynamics studies by administration of the optimised formulation of ramipril observed a significant reduction in mean systolic BP to $112.16 \mathrm{of} \mathrm{Hg}$ after $0.5 \mathrm{~h}$ and $110.21 \mathrm{~mm}$ of $\mathrm{Hg}$ in $2 \mathrm{~h}$ i.e., animals reaches to normotensive state due to faster onset of action attributed by enhanced bioavailability potential of mucoadhesive formulations. The prepared formulations were found to be stable under accelerated stability studies for three months. This confirmed that mucoadhesive microcapsules can be an alternative dosage form for effective delivery of ramipril.

\section{CONFLICT OF INTERESTS}

The author(s) confirm that this article content has no conflict of interest.

\section{REFERENCES}

1. Modi SA, Gaikwad PD, Banker VH, Pawar SP. Sustained release drug delivery system a review. Int J Pharm Res Dev 2011;2:147-60.

2. Chen X, Wen H, Park K. Challenges and new technologies of oral controlled release, oral controlled release formulation design and drug delivery: Theory to Practice, Chapter-16; 2010. p. 257-7.

3. Rao R, Yadav A, kulkarni U. Formulation and evaluation of zeroorder release glipizide bilayer matrix tablets using natural and synthetic polymers. Int J Curr Pharm Res 2010;2:34-42.

4. Mohite PB, khanage SG, Harishchandre VS, Yogita S. Recent advances in microsponges drug delivery system. J Crit Rev 2016;3:9-16.

5. Tahami KL. Preparation, characterization, and in vitro release of ketoprofen loaded alginate microspheres. Int J Appl Pharm 2014;6:9-12.

6. Jagdale S, Dangat Y, Kuchekar B. Improvement of dissolution rate of ramipril by solid dispersion technique and development of buccal patch. Int J Pharm Pharm Sci 2012;4:309-18.

7. Martindale. The complete drug reference. $3^{\text {th }}$ Edition; 2004. p. 1246.

8. Shafiq-un-Nabi S, Shakeel F, Talegaonkar S, Ali J, Baboota S, Ahuja A, et al. Formulation development and optimisation using nanoemulsion technique, A technical note. AAPS PharmSciTech 2007;8:E12-E17.

9. Kolli RG, Reddy VM, Patil CC, Kulkarni RV, Kalyani NV. Formulation and evaluation of matrix tablet of ramipril. Pharma Innovation J 2015;4:26-9.

10. Ekambaram P, Abdul HS. Formulation and evaluation of solid lipid nanoparticles of ramipril. J Young Pharm 2011;3:216-20.

11. Belgamwar V, Shah V, Surana SJ. Design and development of oral mucoadhesive multiparticulate system containing Atenolol, in vitro-in vivo characterization. Chem Pharm Bull 2010;58:1168-75.

12. Das MK, Maurya DP. Evaluation of diltiazem hydrochloride loaded mucoadhesive microspheres prepared by emulsification-internal gelation technique. Acta Poloniae Pharm Drug Res 2008;5:249-59.

13. Singh B, Kumar R, Ahuja N. Optimizing drug delivery systems using systematic "Design of Experiments." Part I, fundamental aspects. Crit Rev Ther Drug Carrier Syst 2004;22:27-105.

14. Singh B, Raza K, Beg S. Developing "Optimized" drug products employing "Designed” Experiments. Chem Ind Dig 2013;12:1-7.

15. Singh B, Ahuja N. Response surface optimisation of drug delivery systems. NK Jain. (Ed.) Progress in controlled and 


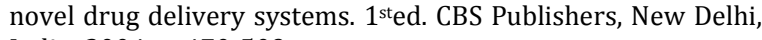
India; 2004. p. 470-509.

16. Box GE, Behnken D. Some new three level designs for the study of quantitative variables. Technometrics 1960;2:455-75.

17. Taguchi G. A System of Experimental Design. Unipub/Kraus International Publications White Plains NY; 1987.

18. Lundstedt T, Seifert E, Abramo L, Thelin B, Nystrom A, Pettersen J, et al. Experimental design and optimisation. Chemom Intell Lab Syst 1998:42:3-40.

19. Doornbos CA, Haan PD. Optimization techniques in formulation and processing. In: J Swarbric K, JC Boylan. Eds. Encyclopedia of pharmaceutical technology, Marcel Dekker: New York; 1995. p. 77-160.

20. Kuehl RO. The design of experiments, statistical principles of research design and analysis; Duxbury/Thomson Learning; Pacific Grove CA; 2000.

21. Swain S, Behera A, Dinda SC, Patra CN, Jammula S, Beg S, et al. Formulation design, optimization and pharmacodynamic evaluation of sustained release mucoadhesive microcapsules of venlafaxine $\mathrm{HCl}$. Indian J Pharm Sci 2014; 76:267-78.

22. Sharma HK, Pradhan SP, Sarangi B. Preparation and in vitro evaluation of enteric controlled release pantoprazole are loaded microbeads using natural mucoadhesive substance from Dillenia indica. Int J PharmTech Res 2010;2:542-51.

23. Swain S, Behera U, Beg S, Sruti J, Patro CN, Dinda SC, et al. Design and characterization of enteric-coated controlled release mucoadhesive microcapsules of rabeprazole sodium. Drug Dev Ind Pharm 2012;39:548-60.

24. Chowdary KP, Rao YS. Design and in vitro and in vivo evaluation of mucoadhesive microcapsules of glipizide for oral controlled release, a technical note. AAPS PharmSciTech 2003;4:E39.
25. Nayak AK, Hasnain MS, Beg S, Alam MI. Mucoadhesive beads of gliclazide, Design.; development and evaluation. Sci Asia 2010;36:319-25.

26. Loyd A, Nicholas GP. Pharmaceutical dosages forms and drug delivery systems: powders and granules. $9^{\text {th }}$ ed. New Delhi, Wolters Kluwer/lippincott Williams and Wilkins; 2011. p. 184-202.

27. Nayak BS, Ghosh SK, Tripati K, Patro B. Preparation and characterization of famotidine microcapsule employing mucoadhesive polymers in combination to enhance gastro retention for oral delivery. Int J Pharm Sci 2009;1:112-20.

28. Tiwari SB, Murthy TK, Pai MR, Mehta PR, Chowdary PB Controlled release formulation of tramadol hydrochloride using hydrophilic and hydrophobic matrix system. AAPS PharmSciTech 2003;4:1-6.

29. Arya RKK, Vijay JA, Singh R. Development and evaluation of gastro-resistant microspheres of pantoprazole. Int J Pharm Pharm Sci 2010;2:1575-80.

30. Albertini B, Passerini N, Sabatino MD, Vitali B, Brigidi P. Polymer-lipid-based mucoadhesive microspheres prepared by spray-congealing for the vaginal delivery of econazole nitrate. Eur J Pharm Sci 2009;36:591-601.

31. Swain S, Meher D, Patra CN, Jammula S, Dinda SC. Design and characterization of sustained release mucoadhesive microspheres of tolterodine tartrate. Curr Drug Delivery 2013;10:413-26.

32. Pouton CW. Effects of inclusion of a model drug on the performance of self-emulsifying formulations. J Pharm Pharmacol 1985;37:1-11.

\section{How to cite this article}

- $\quad$ Korlapati Venkateswara Rao, VV Venkatchalam. Sustained release mucoadhesive microcapsules of ramipril by ionic gelation technique: formulation design, optimization and characterization Int J Pharm Pharm Sci 2017;9(2):128-141. 